\title{
Gastrointestinal Stromal Tumor in a Patient with Neurofibromatosis: Abscess Formation in the Tumor Leading to Bacteremia and Seizure
}

\author{
Maki Kitagawa ${ }^{a, b}$ Toshimori Koh ${ }^{b}$ Noboru Nakagawa ${ }^{b}$ \\ Yutaka Kondo $^{a}$ Minoru Nishio $^{b}$ Atsushi Oguro ${ }^{b}$

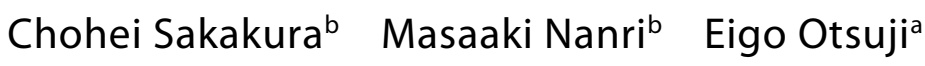 \\ ${ }^{a}$ Division of Digestive Surgery, Department of Surgery, Kyoto Prefectural \\ University of Medicine, Kyoto, and bepartment of Surgery, Shakaihoken Kobe \\ Central Hospital, Kobe, Japan
}

\section{Key Words}

Gastrointestinal stromal tumor - Neurofibromatosis · Abscess · Bacteremia - Seizure

\begin{abstract}
A 66-year-old woman with neurofibromatosis type 1 (NF1) was brought to the emergency room with seizures and high-grade fever. Seizure in adult NF1 patients raises concern for intracranial lesions. However, neurological examination and central nervous system imaging failed to detect any causative intracranial lesions for her seizure. Gram-positive cocci, Streptococcus anginosus, were detected by blood cultures. Abdominal computed tomography revealed a well-defined round mass $7 \mathrm{~cm}$ in diameter, which was found to be a small intestinal gastrointestinal stromal tumor (GIST) containing an abscess. There was fistula formation between the intestinal lumen and the abscess, in which there were numerous Gram-positive cocci. The seizure may have been caused by hypoosmolality (hyponatremia and hypoproteinemia), which may result from decreased food intake associated with high-grade fever and general malaise. In this case GIST originating from the small intestine was invaded by S. anginosus through a fistula, leading to abscess formation, bacteremia, high-grade fever, and seizure, which was the first clinical manifestation.
\end{abstract}




\begin{tabular}{c|l|l|l}
$\begin{array}{c}\text { Case Reports in } \\
\text { Gastroenterology }\end{array}$ & $\begin{array}{l}\text { Case Rep Gastroenterol 2010;4:435-442 } \\
\text { DOI: 10.1159/000321523 }\end{array}$ & $\begin{array}{l}\text { Published online: } \\
\text { October 16, 2010 }\end{array}$ & $\begin{array}{l}\text { O 2010 S. Karger AG, Basel } \\
\text { ISSN 1662-0631 } \\
\text { www.karger.com/crg }\end{array}$ \\
\hline
\end{tabular}

\section{Introduction}

Neurofibromatosis type 1 (NF1), or von Recklinghausen's disease, is an autosomal dominant genetic disorder which causes tumors growing along various types of nerves. The tumors include optic pathway tumors, meningioma, cerebral glioma, and malignant peripheral nerve sheath tumors. NF1 is also a disease with a wide range of neurological manifestations other than nervous system tumors, including lacunar stroke, white matter disease, facial palsy, radiculopathy, and polyneuropathy. The non-nervous tissues such as bones and skin are also affected. NF1-associated gastrointestinal stromal tumors (GISTs) are rare and less than $5 \%$ of all GISTs reported [1]. GISTs in NF1 patients have a high predilection to the small intestine $[2,3]$. Abdominal pain, followed by gastrointestinal bleeding, is the most common presenting clinical manifestation of GISTs. Here, we report a patient with NF1 who presented with seizure as the first clinical manifestation, leading to recognition of the presence of GIST, which was responsible for the seizure.

\section{Case Report}

A 66-year-old woman was brought to the emergency room with partial seizures with secondary generalization, followed by unconsciousness. The clonic seizure started at the right extremities with conjugate eye deviation to the right. On presentation, temperature was $39.4^{\circ} \mathrm{C}$, blood pressure $108 / 62 \mathrm{~mm} \mathrm{Hg}$, heart rate $72 / \mathrm{min}$, and oxygen saturation $96 \%$ while she was breathing ambient air. Her lungs were clear to auscultation. Her cardiac examination was normal, without a murmur or rub. Her electrocardiogram was normal. She had mild edema on her lower extremities and showed neither nuchal rigidity nor Kernig sign. She had NF1 and hypercholesterolemia, which was treated with pravastatin. Many cutaneous tumors and café au lait spots, which were associated with NF1, were found over her body surface (fig. 1). She had a soft abdomen with normal bowel sounds. A fist-sized mass was palpable in the lower abdomen. She had no history of seizures, head injury, drug abuse, mental retardation, or dementia. Red blood cell count was $3.31 \times 10^{6} / \mathrm{mm}^{3}$, hemoglobin level $10.3 \mathrm{~g} / \mathrm{dl}$, hematocrit $30.1 \%$, platelet count $112,000 / \mathrm{mm}^{3}$, and white cell count $12,400 / \mathrm{mm}^{3}$, with $87.1 \%$ neutrophils, $0.1 \%$ eosinophils, $6.5 \%$ monocytes, and $4.7 \%$ lymphocytes. Prothrombin time was $10.9 \mathrm{~s}$ (international normalized ratio 0.91), activated partial thrombin time was $29.5 \mathrm{~s}$, and fibrinogen level was $710 \mathrm{mg} / \mathrm{dl}$. The serum C-reactive protein level was $14.61 \mathrm{mg} / \mathrm{dl}$ (normal $<0.3 \mathrm{mg} / \mathrm{dl}$ ), blood urea nitrogen $5 \mathrm{mg} / \mathrm{dl}$, creatinine $0.31 \mathrm{mg} / \mathrm{dl}$, sodium $126 \mathrm{mmol} / \mathrm{l}$, potassium $4.0 \mathrm{mmol} / \mathrm{l}$, chloride $94 \mathrm{mmol} / \mathrm{l}$, calcium $7.9 \mathrm{mg} / \mathrm{dl}$, total protein $4.5 \mathrm{~g} / \mathrm{dl}$, albumin $1.8 \mathrm{~g} / \mathrm{dl}$, aspartate aminotransferase $51 \mathrm{U} / \mathrm{l}$, alanine aminotransferase $54 \mathrm{U} / \mathrm{l}$, alkaline phosphatase $638 \mathrm{U} / \mathrm{l}$, total bilirubin $0.9 \mathrm{mg} / \mathrm{dl}$, and soluble interleukin-2 receptor $1,260 \mathrm{U} / \mathrm{ml}$ (normal $220-530 \mathrm{U} / \mathrm{ml}$ ).

Cranial computed tomography (CT) revealed that there was slight dilatation of the ventricles, but no lesions compatible with intracranial hemorrhage and tumors. Magnetic resonance imaging (MRI) showed that there were high-intensity areas around the ventricles on T2-weighted images (fig. $2 \mathrm{a}$ ), a finding compatible with lacunar infarction. However, diffusion-weighted imaging showed no lesions compatible with recent cerebral infarction (fig. 2b). The examination of cerebrospinal fluid revealed that white cell count and glucose level were within normal limits, anti-HSV IgG level was 0.48 (normal $<0.20$ ), PCR for DNA of Mycobacterium tuberculosis was negative, and India ink preparation for Cryptococcus was negative. Electroencephalography showed diffuse slow activity without any abnormal discharges.

The high-grade fever, neutrophilia, and the increased levels of C-reactive protein and fibrinogen suggested that she had bacterial infection. The neurological examination and the central nervous system imaging failed to detect any causative intracranial lesions for her seizure. We suspected that she had bacterial infection which might be directly or indirectly associated with her seizure. Venous blood was drawn for bacterial examination, and thereafter intravenous administration of antibiotics (sulbactam/cefoperazone) was started. Within several days after the treatment with antibiotics, she became afebrile with normalization of the white cell count, and no more seizures occurred. Gram-positive cocci, Streptococcus anginosus, were detected by cultivation of venous blood. These findings indicate that she had bacteremia, the causative bacteria being $S$. anginosus, although the 
primary infectious focus was still unknown. Members of the S. anginosus group are part of the normal flora of the human oral cavity and gastrointestinal tract, with the ability to cause abscesses and systemic infections. The unique characteristic of the $S$. anginosus group that sets these streptococci apart from other pathogenic streptococci, such as $S$. pyogenes and S. agalactiae, is their ability to cause abscesses. Positive blood cultures for members of the $S$. anginosus group should prompt consideration of occult abdominal infection, metastatic abscesses, and infective endocarditis [4].

Chest and abdominal CT performed on admission showed that there was pleural effusion at both sides and a large amount of ascites (fig. 2c). Abdominal CT also revealed a well-defined round mass $7 \mathrm{~cm}$ in diameter in the abdominal cavity, which was enhanced by intravenous contrast material. The central area was unenhanced, suggesting that this area had become necrotic. The mass appeared to contain a gas-filled cavity. The CT scan performed a few days later showed that the mass had moved to the left, indicating that it was movable (fig. 2d). Superior mesenteric arteriography revealed that the tumor was hypervascular and was supplied by several jejunal branches from the superior mesenteric artery (fig. 2e). The carcinoembryonic antigen level was $6.0 \mathrm{ng} / \mathrm{ml}$ (normal $<5 \mathrm{ng} / \mathrm{ml}$ ), and the CA19-9 level was $9.8 \mathrm{U} / \mathrm{ml}$ (normal $<37 \mathrm{U} / \mathrm{ml}$ ). No pathogenic bacteria were found by the culture of feces, and no occult blood was detected in feces.

It was suggested that the tumor originated from the small intestine because it was mobile and supplied by several jejunal branches from the superior mesenteric artery. A gas-filled cavity in the tumor suggested that this cavity might communicate with the intestinal lumen. Although the tumor was as large as $7 \mathrm{~cm}$ in diameter, the patient had no signs of gastrointestinal obstruction. In addition, the levels of carcinoembryonic antigen and CA19-9 were not increased. These findings suggested that the tumor might be of non-epithelial origin. The presence of pleural effusion and ascites suggested that the tumor might be malignant, although it was also possible that pleural effusion and ascites were caused by hypoproteinemia. We suspected that she had GIST, since it was reported that the small intestinal tumor most commonly observed in NF1 patients was GIST [2,3], and the findings of examinations were compatible with the diagnosis of GIST.

Laparoscopy-assisted operation was performed on the suspected diagnosis of GIST. A small amount of serous ascites was found. The tumor was located at the jejunum $20 \mathrm{~cm}$ anal from the ligament of Treitz, extending into the small bowel mesentery. No additional tumors were found on the other sites. The tumor was removed by partial resection of the jejunum. Postoperative recovery was uneventful. The removed tumor was $6 \mathrm{~cm}$ in diameter, and an abscess was found in it. There was fistula formation between the intestinal lumen and the abscess (fig. $3 \mathrm{a}, \mathrm{b}$ ). Histological examination revealed that the tumor consisted of palisading spindle cells with nuclear atypia (fig. $3 \mathrm{c}$ ). The mitotic cells were found to be less than 5 per 50 consecutive high-power fields. Immunohistochemical staining showed that the tumor cells were positive for KIT (fig. 3d), and negative for CD34, S-100, desmin, and $\alpha$-smooth muscle actin. The pathological findings confirmed that the tumor was a malignant GIST with intermediate risk. Hematoxylin-eosin and Gram staining revealed that there were numerous Gram-positive cocci in the abscess of the tumor, which were reasonably considered to be the same bacteria as those causing bacteremia (fig. 3e). Genetic analysis showed that the tumor expressed wild-type KIT with normal sequences of exon 9,11,13, and 17, and the wild-type PDGFRA with normal sequences of exon 12 and 18. Cytological analysis showed that there were no malignant cells in the ascites fluid obtained at operation.

\section{Discussion}

The major initial symptoms of this NF1 patient were seizure and high-grade fever with neutrophilia. Therefore, we initially looked for intracranial lesions, in particular intracranial tumors, cerebrovascular diseases, and cerebral abscess, as the cause of her seizure. In fact, intracranial tumors often occur in NF1 patients [5], and cerebrovascular diseases commonly occur at this age in women [6]. However, we could not find any significant intracranial lesions which could have caused her seizure. The detection of Gram-positive cocci, S. anginosus, by blood cultures was surprising and unexpected, because she was unlikely to be immunocompromised and exhibited no signs of disseminated intravascular coagulation. In any case, administration of antibiotics and 


\begin{tabular}{|c|c|c|c|}
\hline $\begin{array}{l}\text { Case Reports in } \\
\text { Gastruenterolooy }\end{array}$ & $\begin{array}{l}\text { Case Rep Gastroenterol 2010;4:435-442 } \\
\text { DOI: } 10.1159 / 000321523\end{array}$ & $\begin{array}{l}\text { Published online: } \\
\text { October 16, } 2010\end{array}$ & $\begin{array}{l}\text { O } 2010 \text { S. Karger AG, Basel } \\
\text { ISSN 1662-0631 } \\
\text { www.karger.com/crg }\end{array}$ \\
\hline
\end{tabular}

electrolyte solutions relieved seizure, fever, and neutrophilia promptly, indicating that her seizure may have been closely associated with bacteremia. Although septic emboli can cause seizures, no such lesion was detected by CT and MRI. She explained that she had had several episodes of high-grade fever during the preceding several days before being brought to our hospital, and that high-grade fever and general malaise had prevented her from taking enough foods. She lived alone and had no person to help her. Decreased food intake may have resulted in decreased serum sodium $(126 \mathrm{mmol} / \mathrm{l})$ and protein $(4.5 \mathrm{~g} / \mathrm{dl})$ concentrations, leading to decreased plasma osmolality. It is plausible that her seizure may have been caused by a rapid decrease in plasma osmolality and concomitant high-grade fever with bacteremia. The symptoms that may be seen with hyponatremia are reported to be related to the severity and, in particular, the rapidity of onset of change in plasma sodium concentration [7]. She had hypocalcemia, which can cause seizures. As she had also hypoalbuminemia, the serum calcium level was corrected for the abnormality in albumin. The corrected calcium level $(9.5 \mathrm{mg} / \mathrm{dl})$ was in the normal range, suggesting that her seizure was unlikely to be caused by hypocalcemia.

Another important finding observed in this NF1 patient was an abdominal tumor. The tumor was movable and supplied by the superior mesenteric artery, suggesting that the tumor originated from the small intestine. The literature shows that the tumor of the small intestine most commonly observed in NF1 patients is GIST [2,3]. In agreement with the literature, surgical intervention revealed that her abdominal tumor was a GIST. Interestingly, there was an abscess in the tumor, and the abscess communicated with the intestinal lumen through a fistula. In addition, there were numerous Gram-positive cocci in the abscess, suggesting that the primary infectious focus causing bacteremia was GIST itself.

GISTs, the most common mesenchymal neoplasms of the gastrointestinal tract, are believed to originate from interstitial cells of Cajal or their stem cell-like precursors [1]. GISTs are defined by their immunohistochemical expression of KIT (CD117), and are neoplasms that are distinctly different from leiomyosarcomas, neurofibromas, and schwannomas [8]. GISTs occur commonly in the elderly (median age 55-60 years) and rarely in children. NF1-associated GISTs are rare and $<5 \%$ of all GISTs reported [1]. GISTs are found in stomach (60\%), small intestine (35\%), and other sites $(<5 \%)$, including the rectum, esophagus, omentum, and mesentery; most GISTs found in the latter two sites are metastatic [9]. Abdominal pain, followed by gastrointestinal bleeding, is the most common presenting clinical manifestation of GISTs. Tumor rupture or gastrointestinal obstruction may also occur [10]. CT scans do not show evidence of ascites or liver metastasis in most GIST patients [11]. Ascites observed in our case may be ascribed to hypoproteinemia, but not metastasis.

Both tumor size and the mitotic activity of tumor cells are predictive factors for the prognosis of GISTs. Small intestinal tumors may behave more aggressively than gastric tumors [12]. Mutations of KIT or PDGFRA gene are also predictive factors for the prognosis, which are associated with the responsiveness to the treatment with imatinib [13]. Mutually exclusive mutations in KIT or PDGFRA receptor tyrosine kinase proteins, which are detected in more than $80 \%$ of GISTs, are central in sporadic GIST pathogenesis. These mutations are found only in the tumor tissue. By contrast, constitutional mutations are found in all somatic cells of the body and are inheritable in the case of familial GISTs. Interestingly, as observed in our case, KIT and PDGFRA mutations are lacking in most NF1-associated GISTs, a remarkable difference from the other types of GISTs [3]. GISTs 


\begin{tabular}{r|l|l|l}
$\begin{array}{c}\text { Case Reports in } \\
\text { Gastroenterology }\end{array}$ & $\begin{array}{l}\text { Case Rep Gastroenterol 2010;4:435-442 } \\
\text { DOI: 10.1159/000321523 }\end{array}$ & $\begin{array}{l}\text { Published online: } \\
\text { October 16, 2010 }\end{array}$ & $\begin{array}{l}\text { O 2010 S. Karger AG, Basel } \\
\text { ISSN 1662-0631 } \\
\text { www.karger.com/crg }\end{array}$ \\
\hline
\end{tabular}

lacking KIT and PDGFRA mutations have been shown to be resistant to the treatment with imatinib [14]. Other characteristics of NF1-associated GIST are as follows: GISTs in NF1 patients have a high predilection to the small intestine, tumors are often multiple, mitotically inactive, and clinically indolent, and the majority of the tumors are small [2]. Moreover, GISTs are often the initial clinical presentation of adult NF1 patients, who, like our case, have subtle subcutaneous and neurologic stigma of the disease [15]. In this case, GIST originating from the small intestine was invaded by bacteria (S. anginosus) possibly through a fistula, leading to abscess formation, bacteremia, high-grade fever, and consequently hypoosmolality (hyponatremia and hypoproteinemia), which in turn caused the seizure. This case presented seizure as the first clinical manifestation, leading to recognition of the presence of GIST, which was responsible for the seizure.

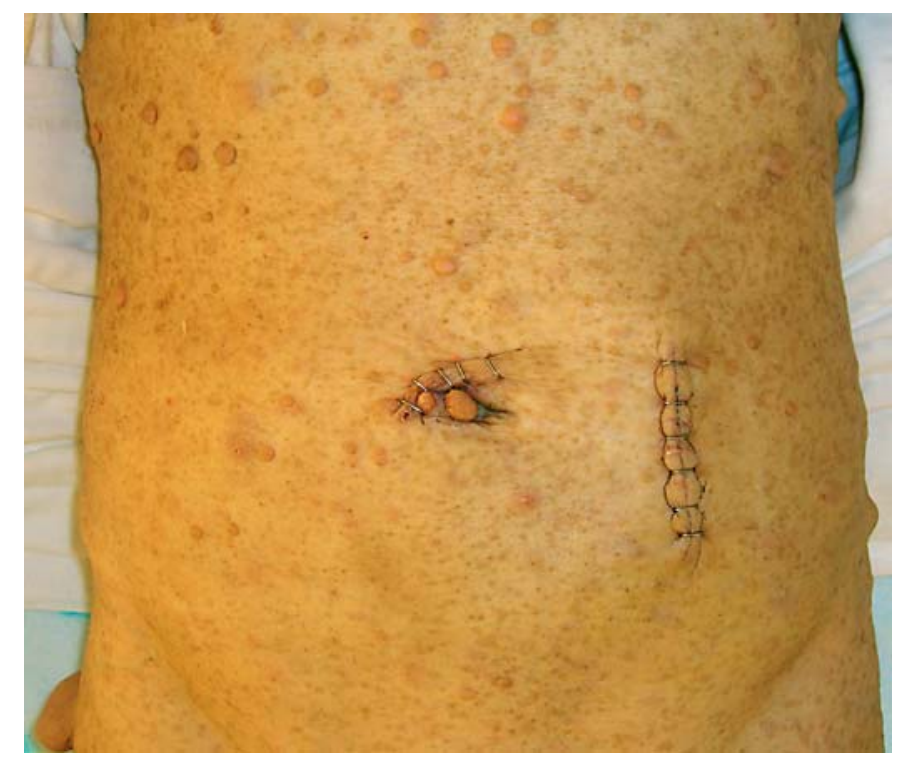

Fig. 1. Many cutaneous tumors and café au lait spots were found over the patient's body surface. Periumbilical and transrectal incisions are ascribed to laparotomy. 


\begin{tabular}{r|l|l|l} 
Case Reports in & $\begin{array}{l}\text { Case Rep Gastroenterol 2010;4:435-442 } \\
\text { DOI: 10.1159/000321523 }\end{array}$ & $\begin{array}{l}\text { Published online: } \\
\text { October 16, 2010 }\end{array}$ & $\begin{array}{l}\text { ○ 2010 S. Karger AG, Basel } \\
\text { ISSN 1662-0631 } \\
\text { www.karger.com/crg }\end{array}$ \\
\hline
\end{tabular}
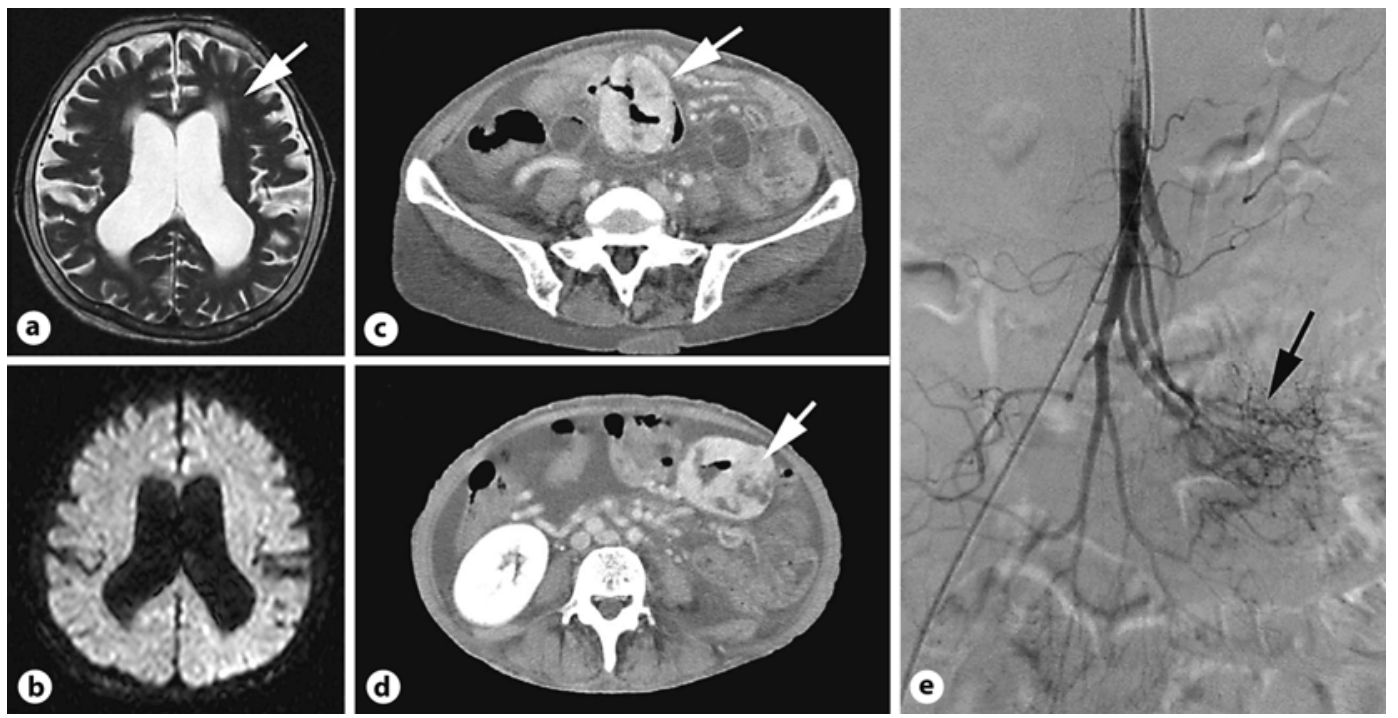

Fig. 2. a MRI showed that there were slight dilatation of the ventricles and high-intensity areas (arrow) around the ventricles on T2-weighted images. b Diffusion-weighted imaging showed no lesions compatible with recent cerebral infarction. c Abdominal CT showed a large amount of ascites and a well-defined round mass (arrow) in the abdominal cavity, which was enhanced by intravenous contrast material. d CT scan performed a few days later showed that the mass had moved to the left. It appeared to contain a gas-filled cavity. e Superior mesenteric arteriography revealed that the tumor was hypervascular and supplied by several jejunal branches from the superior mesenteric artery (arrow). 


\begin{tabular}{r|l|l|l} 
Case Reports in & $\begin{array}{l}\text { Case Rep Gastroenterol 2010;4:435-442 } \\
\text { DOI: } 10.1159 / 000321523\end{array}$ & $\begin{array}{l}\text { Published online: } \\
\text { October 16, 2010 }\end{array}$ & $\begin{array}{l}\text { ISSN 1662-0631 Karger AG, Basel } \\
\text { ISSww.karger.com/crg } \\
\text { wastraenteroloyy }\end{array}$ \\
\hline
\end{tabular}

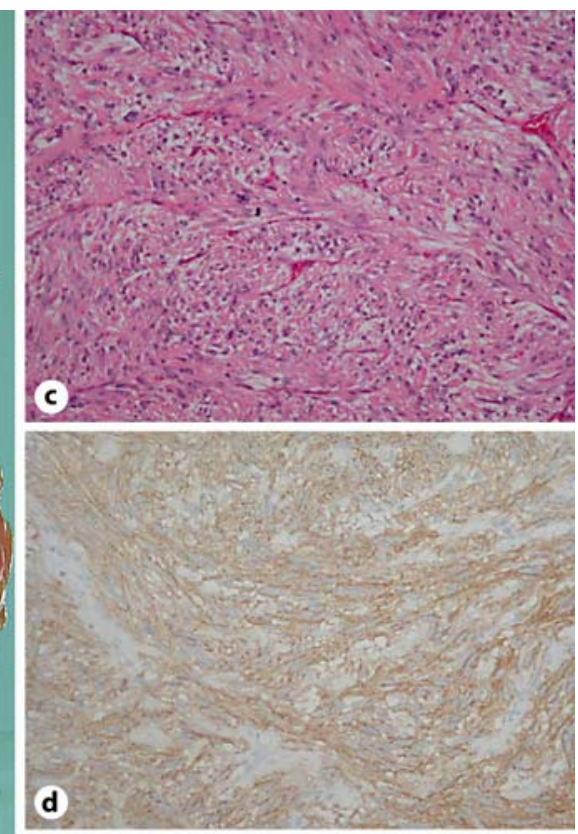

a
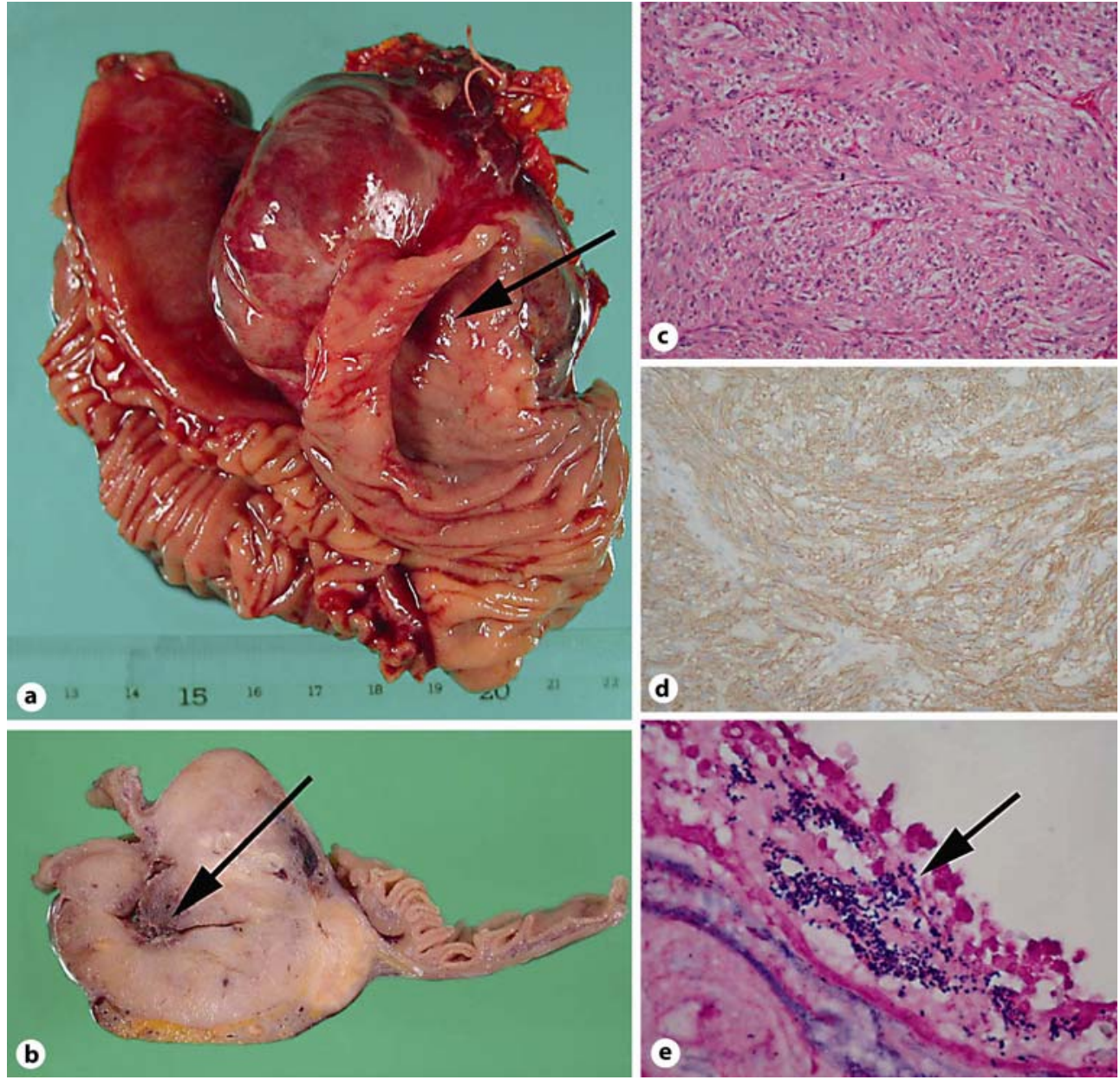

Fig. 3. a, b The removed tumor showed that there was fistula formation between the intestinal lumen and the abscess in the tumor (arrows). c Histological examination revealed that the tumor consisted of palisading spindle cells with nuclear atypia. d Immunohistochemical staining showed that the tumor cells were positive for KIT. e Hematoxylin-eosin and Gram staining revealed that there were numerous Gram-positive cocci in the abscess of the tumor (arrow).

\section{References}

1 Miettinen M, Lasota J: Gastrointestinal stromal tumors: review on morphology, molecular pathology, prognosis, and differential diagnosis. Arch Pathol Lab Med 2006;130:1466-1478.

-2 Miettinen M, Fetsch JF, Sobin LH, Lasota J: Gastrointestinal stromal tumors in patients with neurofibromatosis 1: a clinicopathologic and molecular genetic study of 45 cases. Am J Surg Pathol 2006;30:90-96.

-3 Andersson J, Sihto H, Meis-Kindblom JM, Joensuu H, Nupponen N, Kindblom LG: NF1-associated gastrointestinal stromal tumors have unique clinical, phenotypic, and genotypic characteristics. Am J Surg Pathol 2005;29:1170-1176.

4 Seifert H: The clinical importance of microbiological findings in the diagnosis and management of bloodstream infections. Clin Infect Dis 2009;48:S238-S245.

-5 Créange A, Zeller J, Rostaing-Rigattieri S: Neurological complications of neurofibromatosis type 1 in adulthood. Brain 1999;122:473-481. 
6 Fonarow GC, Reeves MJ, Zhao X: Age-related differences in characteristics, performance measures, treatment trends, and outcomes in patients with ischemic stroke. Circulation 2010;121:879-891.

7 Rose BD, Post TW: Clinical Physiology of Acid-Base and Electrolyte Disorders, ed 5. New York, McGraw-Hill, 2001, pp 716-720, 761-764.

8 Miettinen M, Kopczynski J, Makhlouf HR: Gastrointestinal stromal tumors, intramural leiomyomas, and leiomyosarcomas in the duodenum: a clinicopathologic, immunohistochemical, and molecular genetic study of 167 cases. Am J Surg Pathol 2003;27:625-641.

9 Miettinen M, Lasota J: Gastrointestinal stromal tumors - definition, clinical, histological, immunohistochemical, and molecular genetic features and differential diagnosis. Virchows Arch 2001;438: $1-12$.

10 Tsukuda K, Ikeda E, Takagi S: Multiple gastrointestinal stromal tumors in neurofibromatosis type 1 treated with laparoscopic surgery. Acta Med Okayama 2007;61:47-50.

11 Levy AD, Patel N, Abbott RM, Dow N, Miettinen M, Sobin LH: Gastrointestinal stromal tumors in patients with neurofibromatosis: imaging features with clinicopathologic correlation. AJR Am J Roentgenol 2004;183:1629-1636.

12 Hasegawa T, Matsuno Y, Shimoda T, Hirohashi S: Gastrointestinal stromal tumor: consistent CD117 immunostaining for diagnosis, and prognostic classification based on tumor size and MIB-1 grade. Hum Pathol 2002;33:669-676.

13 Heinrich MC, Corless CL, Demetri GD: Kinase mutations and imatinib response in patients with metastatic gastrointestinal stromal tumor. Clin Oncol 2003;21:4342-4349.

14 Frolov A, Chahwan S, Ochs M: Response markers and the molecular mechanisms of action of Gleevec in gastrointestinal stromal tumors. Mol Cancer Ther 2003;2:699-709.

-15 Boldorini R, Tosoni A, Leutner M: Multiple small intestinal stromal tumours in a patient with previously unrecognised neurofibromatosis type 1: immunohistochemical and ultrastructural evaluation. Pathology 2001;33:390-395. 